\title{
A conceptual framework to understand teachers' Professional Dispositions and Orientation towards tablet technology in secondary schools
}

\author{
Suzanne Sackstein ${ }^{a}$, Lynne Slonimsky \\ a School of Economic and Business Sciences, University of the Witwatersrand, South Africa \\ ${ }^{b}$ School of Education, University of the Witwatersrand, South Africa
}

\begin{abstract}
While recent technological innovations have resulted in calls to incorporate tablets into the classroom, schools have been criticised for not taking advantage of what the technology has to offer. Past research has shown that teachers do not automatically choose to adopt technology in the classroom. A number of concerns exist in relation to the research being conducted within this area. Firstly, the majority of research studies have not been based on sound conceptual frameworks. Secondly, for the most part, these research studies have tended to focus on the technology itself rather than the resulting changes in teaching and learning. Finally, much of the literature is premised on constructivist pedagogic practices which offer promissories of radical pedagogic change. An understanding of technology teachers' orientations to the new technology, coupled with an understanding of the reasons behind teachers' choices to adopt or not adopt technology has not yet been fully explored. From a review of the literature in relation to teachers' Professional Dispositions, derived from the work of Bernstein on the pedagogic discourse, alongside Hooper and Rieber's model on educational technology adoption a conceptual framework has been developed to will shed light on secondary school teachers' differential adoption of tablet technology.
\end{abstract}

Keywords: educational technology, tablet technology, professional disposition, orientation towards tablet technology, pedagogical discourse, technology adoption, secondary education

Categories: • Applied computing $\sim$ Education $\bullet$ Applied computing $\sim$ E-learning $\bullet$ Applied computing $\sim$ Interactive learning environments

\section{Email:}

Suzanne Sackstein suzanne.sackstein@wits.ac.za (CORRESPONDING), Lynne Slonimsky lynne.slonimsky@wits.ac.za

\section{Article history:}

Received: 28 Feb 2017

Accepted: 15 Sep 2017

Available online: 13 Oct 2017

Sackstein, S. and Slonimsky, L. (2017). A conceptual framework to understand teachers' Professional Dispositions and Orientation towards tablet technology in secondary schools. South African Computer Journal 29(2), 66-86. https: //doi.org/10.18489/sacj.v29i2.469

Copyright (C) the author(s); published under a Creative Commons NonCommercial 4.0 License (CC BY-NC 4.0). $S A C J$ is a publication of the South African Institute of Computer Scientists and Information Technologists. ISSN 1015-7999 (print) ISSN 2313-7835 (online). 


\section{BACKGROUND AND CONTEXT}

The utilisation of technology in the classroom is not a new phenomenon. Since the beginning of the 20th century, new technological developments have been promoted or offered as promissories that would radically change pedagogic practices in schools and strengthen teaching and learning (Cuban, 1993). Currently, technological innovations, such as mobile technologies, and more specifically tablets, are being advocated as a powerful means for radically transforming teachers' pedagogic practices and enhancing learning in schools. Within South Africa, huge investments are being made to provide state schools with tablet technology in order to build "classrooms of the future" that are able to create more relevant and engaged teaching and learning environments (Department of Education, RSA, 2004; Motshekga, 2015). According to Clarke, Svanaes, and Zimmermann (2012) schools have been criticised for not taking advantage of what technology has to offer. Whitefield (2012) claims that secondary schools are a main area of concern, where pressures such as extensive syllabi, exam structures and subject choices have been listed as reasons for the lack of technology integration. Montrieux, Vanderlinde, Schellens, and De Marez (2015) state that most research studies into the use of tablet technology within education have been conducted in the context of primary or higher education, and thus research into understanding the secondary school landscape is greatly needed.

Increasing calls to incorporate tablet technology into the classroom are arguably being driven by its unique characteristics and the groundswell of popular opinion demanding its inclusion. Despite the increased need to understand the subsequent effects of tablet technology integration and use within an educational context, Blackwell (2013), Clarke et al. (2012), Haßler, Major, and Hennessy (2016) purport that research in this area is still in its infancy, with only a handful of reviews that have studied the use of tablets in an educational setting. In addition to the small number of studies in this area, a number of concerns exist: firstly, from a methodological perspective there are a lack of frameworks being used to carry out the research (Blackwell, 2013); secondly, the narrow technologydriven research focus without consideration of the complexities involved (Clarke et al., 2012); and thirdly, that contemporary research into educational technology and pedagogy especially, but not exclusively, has been conducted by advocates of constructivist learning theories and learner-centred teaching (Jaffer, 2010; Hooper \& Rieber, 1995). From a methodological perspective, Blackwell (2013) claims that the enthusiasm and drive to integrate tablet technology into the classroom has arguably been driven by "anecdotal evidence on mobile technology showing promising influences on learning outcomes" [p. 3] that does not provide an understanding of the issues and effects of the integration of tablets within education (Clarke \& Svanaes, 2014). Green (2014) claims that the relatively limited and fragmented nature of the current knowledge base in relation to tablet technology use within education (Haßler et al., 2016), as well as the lack of conceptual frameworks being employed to guide the entire process, make it exceedingly difficult to draw any conclusion from the majority of research in this area. Conceptual frameworks are not only used to assist researchers in framing research questions and ensuring that there is coherence within the research study, but can also be developed as an outcome of the research in order to facilitate future replicable research being conducted (Green, 2014). In addition to methodological concerns, the research in this area 
is inundated by studies measuring the presence, functionality, quality (Clarke et al., 2012), and stages of adoption of the technology (Hooper \& Rieber, 1995). The research explicitly aimed at understanding teachers' orientations and perceptions of the new technology at stake appears to be limited . The concern in relation to the constructivist nature of research into the use of technology in the classroom, with the learner as central (Jaffer, 2010) has been presented within the body of this article as it requires an in-depth review of the literature.

This article aims to address the absence of rigorous research, lack of teacher focus, and scarcity of research studies within secondary education, by developing a conceptual framework using teachers' Professional Dispositions (PD) and their Orientations towards Tablet Technology (OTT). The intention being to provide a solid foundation by which the underlying reasons related to teachers' tablet adoption choices can be studied and better understood. Potentially, this conceptual framework will enable researchers to carry out evidenced-based studies in which findings are meaningful and accessible to others (Polit \& Beck, 2010). The use of such a framework will shed light on teachers' differential adoption of tablet technology in contexts and settings where tablet technology is either available, being advocated by school management, or even required by the educational stakeholders and government policies.

\section{DEMANDS TO INCLUDE TECHNOLOGY IN THE CLASSROOM}

Educators are facing ever-increasing demands to integrate and utilize tablet technology in the classroom, with the expectation that tablet technology will improve the quality of education they offer. There are a range of possible reasons for this demand. One possible reason may be attributed to an argument that learners are digital natives that have different orientations to learning and to knowledge, whereas teachers are digital immigrants, since they are being gradually forced to adopt technology later on their lives (Prensky, 2001). According to Prensky (2001) there is an overwhelming gap between learners and their 'digital immigrant' instructors, which demands a radical transformation of formal educational environments. Many researchers have refuted the 'digital native' claim due to its inability to portray the complexity of an entire generation through its homogeneous definition (Jones, 2010). Maton (2007) asserts that while there is a proportion of the younger generation that is extremely adept with technology, there remains a significant proportion that has not yet sufficiently mastered these skills.

Another possible reason for the growing demand to include digital technology in schools may be in response to the enormous technological transformation occurring within contemporary society (Roschelle, Pea, Hoadley, Gordin, \& Means, 2000). Frank, Zhao, and Borman (2004) argue that presently, the prevailing belief is that schools need to implement technology innovations "either because it enhances productivity or because of strong institutionalised legitimacy" [p. 149] and social considerations. Many of those advocating educational technology believe that utilising technology in schools is a critical component necessary to prepare today's learners for the rapidly changing society of digital information and learning (Motshekga, 2015; Wang \& Reeves, 2003). Cobcroft, Towers, Smith, and Bruns (2006) cite external factors, such as market trends and the changing costs of technology; and internal factors, such as learner preferences, staff capabilities and pedagogical 
approaches, as playing key roles in influencing the content and manner of pedagogic discourse required at present. As the use of tablet technology in the classroom increases (Motshekga, 2015), it is necessary to explore the unique nature of this technology as well as the potential benefits that it brings to society in general, and education specifically.

\section{TABLET TECHNOLOGY}

Tablet technology has unique features that make it more desirable than previous technologies such as laptops and desktop computers (Blackwell, 2013). Tablets, according to Clarke and Svanaes (2014), not only surpass prior technologies but also have advantages over other mobile devices such as smartphones and e-reader as they have "larger screens, an increasing variety of interactive apps, greater processing power, greater battery power and the availability of audio and video recording software" [p. 3]. Blackwell (2013) argues that tablet technology is an advance over prior technologies as it offers unique features and different experiences in terms of flexibility, mobile capabilities, ease of use, and multi-function capabilities (Blackwell, 2013; PDST: Technology in Education, 2017).

Tablets became commercially available in 2002, and by 2009 over 14 million tablets had been sold worldwide (Clark \& Luckin, 2013). From 2012 to 2013 Apple reported that the number of iPads being used in educational institutions had tripled and had exceeded 4.5 million users (Paczkowski, 2013). By the end of 2013, while the iPad was still the preferred tablet within an education context, it was clear that the competitors were already catching up (Clark \& Luckin, 2013). Locally, in South Africa, the introduction of tablets in private schools in 2012 began with a number of pilot studies with future plans for extensive roll-outs. Subsequently, in 2015 the Gauteng Department of Education (GDE), handed out 88000 tablets to public secondary school students in 'The Big Switch On'. According to (Motshekga, 2015) the use of tablets in South African schools will facilitate an improvement of educational quality as well as enable classroom teaching to prepare students to cope in a technological society, "exposure to ICT allows learners to develop skills that will give them an edge in an ever-increasingly technology-saturated work environment" (Motshekga, 2015, p. 1).

Tablets offer instant-on capability; 'anytime, anywhere' learning; integrated features and components; availability of a wide range of 'apps'; and personalised ownership and learning opportunities (Blackwell, 2013; Haßler et al., 2016). Firstly, tablets have an instant-on capability that enables a quick start-up and thus saves essential class time in comparison to laptops and desktop computers, which have a long start up time (Blackwell, 2013). Secondly, tablets are wireless computing devices that enable 'anytime, anywhere' learning as the technology can be used outside the classroom (Blackwell, 2013; Clarke \& Svanaes, 2014). The unique characteristics of tablet technology enable learning and teaching to take place both inside and outside of the classroom, as well as any time during the day (Blackwell, 2013, p. 12) without being tied to a computer in a specific location. In addition, the portable nature of the device, Clarke and Svanaes (2014) argue, allows students to build links between school and everyday life and thus create a home-school connection which provides "students with a classroom-experience that relates to their technology-saturated real world" [p. 3].

Thirdly, tablets have integrated features and components that enable for multiple functions to be 
performed by a single device (Clarke \& Svanaes, 2014). The built-in high resolution tablet screens are touch enabled which facilitate direct manipulation and are something that users are familiar with as they are similar to their cellphones and thus, Blackwell (2013) claim, they are more intuitive to use. The integration of a camera, microphone and GPS within a single tablet device enables the gathering of various types of digital data: the camera for capturing videos and photos; the microphone for voice recording; and the GPS to determine geographic location (Haßler et al., 2016; Lovászová, Michaličková, \& Cápay, 2015). Fourthly, the popularity of tablets has led to an interest in the creation and development of 'apps' (Haßler et al., 2016) and therefore there is an increasing availability of a wide range of 'apps' which provide users with of a vast choice of software to address a large range of possible needs (Blackwell, 2013). Finally, tablets are personal tools that provide for the possibility personalised opportunities. According to Clark and Luckin (2013), personalisation can take many forms: ownership of the device; the design of customised learning activities and modified assessments; or personalised choices of software, apps and tools. Tablets are personal tools, which can be used to facilitate a greater sense of responsibility and enable access to personalised learning content to support independent learning (Clarke \& Svanaes, 2014).

The above mentioned reasons, alongside the unique features of tablet technology, enable an understanding of the backdrop of calls to integrate tablet technology within the classroom, but they do not address key educational questions and issues at stake. Jaffer (2010) points out that the majority of contemporary research within the field of educational technology has been premised on the notion of a learner-centred pedagogical view. Proponents of educational technology have cited multiple benefits, including the following: improved literacy and numeracy skills; independent and collaborative learning; individual learner assistance; and improved learner engagement (Attewell, 2005). Wang and Reeves (2003) suggest that constructivist learning theories, in which the learner rather than the teacher is viewed as central, appear to be the ultimate goals towards which technology innovation in the classroom strives. However, Jaffer (2010) points out that although particular pedagogical approaches are neither good nor bad in themselves, the problem is that the majority of educational technology advocates, who believe that technology innovations will promote learnercentred classrooms, have "discarded instructional design as a form of pedagogy" [p. 289].

It is essential to be aware of this predominant orientation to learning and pedagogy if one is interested in researching differential adoption of educational technology by teachers, as those who do not adopt it within the classroom may not hold the same assumptions about learning and/or pedagogy. Several researchers (Cuban, 1986; Hooper \& Rieber, 1995; Kuhn, 2007) claim that past technological innovations within formal education have failed as "the educational system has scarcely changed during the past 50 years" (Hooper \& Rieber, 1995, p. 155). Cuban (1993) argues that educational institutions appear to be less open to educational technologies than other sorts of institutions due to "existing cultural beliefs about what teaching is, how learning occurs, what knowledge is appropriate in schools and the teacher-learner relationship" [p. 155]. Thus, although there is a growing demand to utilize tablet technology in the classroom, technology use within educational contexts is not a simple one dimensional issue. 


\section{TECHNOLOGY WITHIN EDUCATION}

Since the middle of the twentieth century, new educational technologies such as instructional television, multimedia, personal computers, etc. have been introduced into schools to revolutionize teaching and learning (Cuban, 1993). However, as discussed previously, advocates of educational technology use, maintain that past technology innovations have failed to deliver the promissories offered by its campaigners (Cuban, 1986, 1993; Wang \& Reeves, 2003). According to Cuban (1986), teachers either do not shift their pedagogical practices or shift them slowly while technology is evolving at an escalating rate, creating a tension in the teacher-technology relationship. As teachers are still employing traditional pedagogic practices, technology cannot be effectively utilised - as he puts it, 'Computer meets classroom: Classroom wins' (Cuban, 1993). This apparent lack of educational technology integration may also be attributed to a clash between the views of teachers and educational technologists, as educational technologists give the impression that current and traditional pedagogic practices must shift towards more constructivist and less teacher directed pedagogies (Jaffer, 2010; Hooper \& Rieber, 1995) in order to be successful. There are a number of possible reasons for this dominant view being prevalent among those advocating the use of educational technology.

One may be attributed to Constructivism as a learning theory being viewed as preferable to Instructivism (Duffy \& Jonassen, 1992; Hooper \& Rieber, 1995; Kuhn, 2007; Perkins, 1992; Wang \& Reeves, 2003), while the second may be due to a tendency to conflate learning theories and privileged pedagogic practices (Jaffer, 2010). The first reason proposed is based on overwhelming evidence of claims for superiority of Constructivist learning theories within the contemporary educational technology literature (Cuban, 1986, 1993; Hooper \& Rieber, 1995; Reiser, 2001; Roschelle et al., 2000; Wang \& Reeves, 2003). For much of the twentieth century, Instructivism, fuelled by Behaviourist psychology, positioned the teacher as central to the learning process, with knowledge passively acquired by learners but explicitly specified and transmitted by teachers (Jaffer, 2010). Constructivist theories in education, born in response to the rejection of Behaviourism and Instructivism, assert that human beings impose meaning on the world by interacting with the physical, social and mental worlds around them (Duffy \& Jonassen, 1992), created from processing or reflecting on prior experiences (Von Glasersfeld, 1998). Piaget, who developed the theory of Cognitive Constructivism (Swan, 2005), also maintained that learning is undeniably a property of individuals, not teachers. Vygotsky, while in agreement as to the location of knowledge within persons, differed from Piaget in that he claimed that learning is fundamentally a social activity in which the human mind is transformed from its actual developmental level to its potential developmental level by collaboration with more capable peers (Jaffer, 2010; Swan, 2005). Thus the constructivist perspective is frequently accompanied by strong learner-centred pedagogy where the learners are constituted as active participants who must construct their own understanding (Perkins, 1992) with the teacher merely as a facilitator in the knowledge construction process (Wang \& Reeves, 2003).

As noted, much contemporary educational technology research has tended to advocate technology as the enabler for more individualised learning based on learner discovery, thus advocating a shift away from teacher-centred instruction (Wang \& Reeves, 2003), as computers are viewed as 
more cooperative than teachers in enabling the ultimate goal of authentic learning environments controlled by learners (Reiser, 2001). One view mentioned by educational technology proponents, as confirmatory of a constructivist based view, is that instructivist style learning is focussed mainly on presentation, memorisation and recall of content alone, which is outdated given the prolific use of technology and explosion of information within today's society (Duffy \& Jonassen, 1992). Although the ubiquitous standpoint within educational technology literature is one in Constructivism and collective knowledge (Ravenscroft, 2001) is perceived as preferable, Czerniewicz (2010,6) points out that this is not necessarily so clear cut because both proponents of Instructivism and Constructivism propose the use of educational technology. At one extreme, behavioural and instructive views are dominant while on the other extreme, cognitive and constructive views dominate, with neither being viewed superior to each other.

At this point, it is important to be aware that while advocates of constructivist learning theories recognise learners can only learn through the construction of their own understanding and thus propose learner-centred environments, constructivism is not a theory of teaching but rather a theory of learning (Jaffer, 2010). Not all Piagetians and not all Vygotskians believe that it is unimportant to create well-structured learning paths (Jaffer, 2010). Piaget advocated activities should be carefully planned to promote assimilation and accommodation and Vygotsky argued that the mediator within the learning process is crucial in the initiation into scientific concepts or systematised knowledge. However, as Jaffer has noted, there has been a tendency to conflate learning theories and pedagogic practice, thus enabling pedagogic constructivists in discarding "instructional design as a form of pedagogy because of its association with authoritarian ideology and objective knowledge" (Jaffer, 2010, p. 17). Advocates of pedagogic Constructivism downplay the role of the teacher. For example, Perkins (1992) claims that because learners construct meaning based on their experiences, pedagogic practices must therefore actively promote this type of learning in order to enable construction of knowledge to occur.

Jaffer's claim is premised on concepts derived from psychological constructivism which have been incorrectly recontextualised within pedagogic practices. She argues that this view is erroneous for several reasons. Firstly, theories of learning explain the nature of knowledge and how an individual learns, while pedagogy describes the functions and relationships of teachers and learners and the activities they perform. According to Jaffer, theories of learning and pedagogic practices are not equivalent and therefore it is implausible to match underlying psychological theories as decisively shaping the form of pedagogy practiced. Secondly, pedagogic constructivists believe that direct instruction contradicts the very basis of psychological constructivism. Psychological constructivism, however, does not dictate pedagogic practice but rather asserts that individuals learn in the course of constructing knowledge from the world around them irrespective of the specific teaching strategy employed: i.e. "how individuals learn is not dependent on how they are taught" [p. 287]. Thus, according to Jaffer, pedagogic constructivists have erred in deriving pedagogic practice from their preferred constructivist theory of knowing. Finally, Jaffer cites the association of a specific pedagogic practice with a particular learning theory as one with moral implications. Pedagogic practices are neither intrinsically 'good nor bad' but are rather dependant on how they are utilised within the classroom. Pedagogic constructivists have evaluated Instructivist pedagogic practices as inherently 
bad, whilst Constructivist pedagogic practices are perceived as innately good. This perception has influenced educational technologists to discard instructional design with the vision of Constructivism as a learning theory and pedagogic practice as the goal (Kirschner, Sweller, \& Clark, 2006).

However, the bias towards a Constructivist pedagogy may not be the only reason for the apparent lack of educational technology success being advocated by those favouring educational technology integration. Howard and Maton (2011) claim one possible reason for this may be attributed to the fact that much contemporary educational technology research is anecdotal rather than grounded in sound evidence due to a lack of powerful theoretical frameworks being developed in the field of educational technology. Howard and Maton propose that the majority of educational technology research is being carried out in isolation from other research within education, and that this in turn, has contributed to the widespread lack of knowledge being considered as a crucial factor for study. Howard and Maton also point to the dichotomous view of knowledge within educational research as either a psychological or social object of inquiry. Psychology views knowledge merely as information within people's minds, with a central focus on knowing; while sociology views knowledge as a socially constructed reality reflective of dominant societal views. Howard and Maton believe that knowledge is both socially and epistemically constructed and thus exhibits its own properties, powers and tendencies. Howard and Maton contend that knowledge-blindness, with the central focus on characteristics of individuals rather than knowledge itself, results from disparate views of knowledge as either social or epistemic. Therefore, current models regarding educational technology integration, which highlight factors and relations to be explored, are unable to unravel the underlying reasons behind them, due to their lack of consideration of underlying principles relative to the type of knowledge that is being taught and learned. While all subjects and forms of knowledge are generally treated as homogenous in much of the educational technology research, in reality, claim Howard and Maton, this may not be true. Howard and Maton conclude that solid theoretical frameworks, which consider both knowledge and knowledge practices, may provide the resources necessary to unravel the unanswered questions and bias claims of the past.

It is evident from the literature cited regarding the guiding principles of educational technology as a discipline that both pedagogic constructivism and the lack of focus on the importance of knowledge have shaped the psychological and pedagogical views within educational technology. With Constructivism as an educational technology goal, many researchers claim that promises of educational technology benefits have been inhibited by various factors (Wang \& Reeves, 2003). Wang and Reeves identify teachers as one of the primary factors inhibiting integration of technology. Based on their research on teachers' curriculum implementation practices, Hoadley and Ensor (2009) point out that teachers are not simply resistant to change, as new curricula may require teachers to transform their pedagogical practices. One would assume that similar shifts would be required by teachers if they are to change their pedagogical practices to gain from the benefits of educational technology. Given this insight, and Cuban's contention that promises of educational technology have been largely unfulfilled due to "existing cultural beliefs about what teaching is, how learning occurs, what knowledge is accepted in schools and the teacher-learner relationship" (Cuban, 1993, p. 185), it is important to understand how different teachers conceive of learning, pedagogy and knowledge, and whether their orientations to these issues have implications for the form and level 
of their adoption of educational technology. Hoadley and Ensor (2009)'s concept of Professional Dispositions, which is grounded in Bernstein's theory of curriculum and pedagogy and Bourdieu's concept of dispositions, offers a means of investigating the grounds for teachers' choosing whether or not to integrate educational technology in the classroom.

\section{PROFESSIONAL DISPOSITIONS}

According to Hoadley and Ensor (2009), the construct of 'Professional Disposition' connotes "how teachers think and speak about their subject knowledge, learners, pedagogic practice and the relationship between themselves and their learners" [p. 2]. The foundation for this concept is drawn from Bourdieu (1974)'s notion of dispositions. Bourdieu defines disposition as established orientations to thinking and acting constructed within a social context, wherein people see and act accordingly to the world around them. Hoadley and Ensor (2009) contend that while people's ways of viewing the world are socially acquired, manifestations of these propensities are evident within opinions and outlooks of individuals and their practices. To explicitly deal with the role of teachers within the educational field, Hoadley and Ensor (2009) utilised Bernstein's language of description for curriculum and pedagogy 2000, and affixed the word 'professional' to Bourdieu's original notion of disposition 1974. In order to understand how the concept of Professional Disposition builds on Bernstein's language of description, it is necessary to explore Bernstein's theory of pedagogic discourse.

\section{BERNSTEIN'S LANGUAGE OF DESCRIPTION FOR CURRICULUM AND PED- AGOGY}

\subsection{Instructional and regulative discourse}

Bernstein $(1986,1996,2000)$ developed a theory of curriculum, then a theory of pedagogy and then of knowledge to address questions in the sociology of education, particularly in relation to social class and educational access. Bernstein's theory of pedagogic discourse provides a very powerful language of description for systematically describing and investigating any curriculum or pedagogic issues. In order to recognise teachers' Professional Dispositions, relative to their pedagogic interpretations and practices, this study employs Bernstein's theory of pedagogic discourse in the field of reproduction. Pedagogic discourse is a collection of rules which control the transmission or acquisition of systematic knowledge taught in schools and includes a means of systematically describing both content transmitted by teachers and the methodology employed by teachers for its transmission (Morais, 2002).

Bernstein (1986) defines the content of the pedagogic discourse as constituted of two analytically distinct but interrelated discourses, instructional and regulative. Singh (2002) characterizes the instructional discourse as a discourse of competences, related to the rules generating a discipline and its specific knowledge; and the regulative discourse as one which generates social order in relation to 
the rules for appropriate behaviour, character and approach of both teacher and learner within the classroom. The instructional discourse, Morais (2002) asserts, "refers to what is being transmitted" [p. 560], while the regulative discourse is a "discourse of order which translates the dominant values of society and regulates the form of how knowledge is transmitted" [p. 560]. Neither the instructional nor the regulative discourse alone shapes teachers' pedagogic practices but rather, Bernstein (1996) claims, it is their combined product that dictates the transmission of specific knowledge or skills, embedded within a particular, regulative moral order (Hoadley \& Muller, 2010). Neves and Morais (2001) contend that the prevailing moral order is purely a reflection of the dominant principles governing a society at a particular point in time.

\subsection{Classification and framing}

Any pedagogic practice, according to Bernstein (2000), is generated from the same fundamental rules but may vary in strength in relation to knowledge boundaries between subjects and power relations, and boundaries between teachers and learners. Bernstein (1971) has constructed different educational knowledge codes in order to describe these variations within the three 'messages systems' of curriculum, pedagogy and evaluation by employing the concepts classification and framing.

Classification refers to the 'what' of the pedagogic discourse and deals with the power relations that shape the "strength of the boundaries or degree of insulation between discourses" (Bernstein, 2000, p. 6). These symbolic boundaries, constructed by teachers, relate to what knowledge and boundaries are considered valid (Hoadley \& Ensor, 2009). Scott (2007) claims classification exists on a continuum from strong to weak, with strong classification enabling the development of specialised knowledge, whereas weak classification weakens the 'voice' or specialisation of the subject. Framing refers to the 'how' of the pedagogic discourse and deals with the 'locus of control', from several perspectives. Firstly, in relation to "the way in which knowledge is selected, sequenced, paced and evaluated in the classroom" (Hoadley \& Ensor, 2009, p. 2) and secondly, in relation to the style and nature of teacher and learner communication. Framing, like with classification, exists on a continuum from strong to weak. A strong frame enables the teacher to exert more control over the sequence of information presented, the time allowed or allocated to each section as well the style in which information is transmitted; a weak frame allows teachers limited control over the "selection of items and the way it is organised in respect of the pedagogical relationship" (Scott, 2007, p. 77).

Utilising the relative strength and weakness of classification and framing, Bernstein (2000) defined two different codes, collection and integrated. Collection codes exhibit relatively strong framing and classification, whereas integrated codes exhibit relatively weak classification and framing and tend to blur boundaries between subjects, as well as frequently blur the boundaries between everyday and school knowledge (Morais, 2002). Morais (2002) claims that teachers' pedagogic practices, which consist of both the instructional and regulative discourses, are in reality simply an actualisation of their coding orientation in relation to the strength or weakness of the classification and framing within their pedagogic discourse.

Although the concepts of classification and framing provide a means by which the strength of boundaries and power relations of teachers relative to their subject knowledge and their learners can 
be examined, it is still necessary to explore the fundamental elements in relation to 'what' and 'how' subject knowledge is being taught within the classroom. Therefore one needs to think about the way in which the 'what' of knowledge, the instructional discourse, and the 'how' of pedagogy, the regulative discourse, can be described. The study has employed Bernstein's view of the knowledge structures $(1999,2000)$, as vertical and horizontal, to deal with the 'what' of knowledge being transmitted and Bernstein's pedagogic modes (2000) of performance and competence to address the power relations in the classroom. Knowledge structures will now be considered.

\subsection{Horizontal and vertical knowledge structure}

The instructional discourse, as discussed previously, describes the 'what' being taught and encompasses how teachers perceive their subject's knowledge structure as well as subject specific procedures. Bernstein (2000) described strongly classified knowledge as a collection code, and weakly classified knowledge characterised by weak boundaries as an integrated code. Utilising this language of description, Bernstein distinguished between two pedagogic modalities on either end of a continuum, shaped by teachers' positions in relation to the structure or degree of knowledge specialisation, referred to by Bernstein as horizontal or vertical knowledge structures. Bernstein (2000) constructs his conception of vertical and horizontal knowledge structures based on his argument that school and everyday common sense are dissimilar and diverse.

According to Bernstein (1999, 2000), everyday 'common sense' horizontal knowledge is weakly classified and framed. This form of knowledge is usually oral in nature and is characterised as "local, context-dependent, specific, tacit and multi-layered" knowledge (Bernstein, 2000, p. 157). The most critical feature of this knowledge form is that it is segmentally arranged and differs in relation to the manner in which specific cultures segment and highlight certain activities and practices. The circulation of knowledge within in this discourse is not necessarily related to one correct strategy, but rather, is an accumulation of experience within a specific context and community. Vertical discourses, on the other hand, do not have knowledge that is segmentally organised or culturally dependent, but rather consists of "specialised symbolic structures of explicit knowledge" (Bernstein, 2000, p. 160). According to Bernstein, all school knowledge is vertical and thus requires hierarchical sequencing and progression.

Bernstein (2000) further differentiates between two forms of vertical discourses, defined as horizontal and hierarchical knowledge structures as well as the manner in which changes to these different structures transpire. Horizontal knowledge structures consist of a collection of specialised languages and modes of interrogation. Development within this structure results in the introduction of a new language with the "possibility of a fresh perspective, a new set of questions, a new set of connections and problems and most importantly a new set of speakers" (Bernstein, 2000, p. 162), which may be utilised to challenge the legitimacy of current practice. Alternatively, hierarchical knowledge structures "create very general propositions and theories, which integrate knowledge at lower levels" (Bernstein, 2000, p. 161). Change within this structure emerges when attempts are made to disprove or integrate evolving or new propositions.

While the nature and form of pedagogy practiced by teachers within an instructional discourse 
may well be shaped by their view of knowledge structure in which their discipline resides, the discourse chosen by a teacher is often not solely dependent on this factor. The regulative discourse, the 'how' of pedagogic practice, must therefore also be explored.

\subsection{Performance and competence pedagogic modalities}

Pedagogic modality, defined by Bernstein (1996) as the regulative discourse and by Hoadley and Ensor (2009) as the way in which learners are organised for learning and the manner in which knowledge is transmitted, is shaped by the strength of framing present within teachers' pedagogic practices. Bernstein (1996) defined two types of pedagogic modalities, performance and competence. Bernstein positioned performance pedagogic modalities, characterised by strong framing, on the one end of the continuum and at the other end, competence pedagogic modalities, characterised by weak framing.

Using this as a foundation, Naidoo (2011) identified three core elements that could be observed with regards to teachers' authentic pedagogic practice, as a means for a more nuanced understanding of the factors shaping teachers' views of their regulative discourse. The first core element, hierarchical rules, addresses the natural asymmetrical power relations that exist between teacher and learner. Competence pedagogical modalities characterised by weak framing, according to Naidoo, exhibit more obvious learner-control with apparent symmetrical power relations present between teacher and learner. On the other hand, competence pedagogical modalities typified by strong framing are associated with teacher-centred control and asymmetrical teacher-learner power relations (Naidoo, 2011).

The second core element, labelled by Naidoo as 'sequencing and pacing rules', deals with the locus of control in relation to the order in which knowledge is presented and the pace at which it is the acquired. Typical within competence pedagogic modalities is a strong dependency on learners (their features and their specific contexts) for the choice texts and pedagogic practices employed (Bernstein, 1996). On the other end of the continuum, a performance pedagogic modality, typified by strong teacher control and characterised through strong framing, results in authority with regard to content selection, sequencing and pace of instruction residing with the teacher (Bernstein, 1996). Bernstein further asserts that as performance pedagogic modalities are based on specialised subjects, skills or procedures, within this modality it is possible to realize the transmission of knowledge explicitly through texts. However the possibility of pre-packaged textbooks, within a competence pedagogic modality, is limited due to alignment of texts catered to the features of individual learners.

The third core element, 'criteria rules', relates to the practice through which what counts as legitimate recognition and production of epistemic and social relations is realised (Naidoo, 2011). Typical of performance pedagogic modalities is the acquirer's specific output, which is a consequence of specialised skills developed with a particular purpose in mind. Within this modality, output is graded and learners are stratified according to these results (Bernstein, 2000), whereas competence pedagogic modalities are typified by teachers who view differences between acquirers as complementary rather than a justification for stratification and grading, with the fundamental characteristic being the focus on learners as active participants (Christie, 2008). 


\subsection{Professional disposition revisited}

Having introduced Bernstein's language of description for researching curriculum and pedagogy and Bourdieu's conception of dispositions, it is now possible to return to Hoadley and Ensor (2009)'s construct of Professional Dispositions.

The construct of 'Professional Disposition', as defined by Hoadley and Ensor, relates to teachers' orientations to learning, to learners, to the relationship between teachers and learners, and their conceptions of the nature of knowledge to be taught and acquired. It is therefore both a theory of instruction containing assumptions made by teachers in relation to children, how they learn and the subject knowledge to be transmitted and acquired (instructional discourse); as well as a theory of regulation relative to teachers' conceptions of what the relationship between learner and teacher should be relative to appropriate conduct, character and manner in the classroom (regulative discourse). Hoadley and Ensor investigated the instructional discourse by analysing the manner in which teachers spoke about learners, learning and knowledge, with regard to boundaries of their subject knowledge through degrees of classification (Bernstein, 2000). In addition, Hoadley and Ensor analysed how teachers spoke about their subject, as well as their opinions as to the specialisation required by their subject, either as horizontal and vertical knowledge (Bernstein, 2000). In relation to the regulative discourse, Hoadley and Ensor investigated several facets relative to control within these boundaries, through degrees of framing (Bernstein, 2000). In relation to the hierarchical nature of the relationship in the classroom, factors such as pacing, sequencing, selection and pedagogic practices were explored. Concerning learners, how teachers believe people learn, justification and selection of potential resources, visions of the ideal learner, as well as observations of teachers interactions with learners were utilized. Hoadley and Ensor concluded that teachers' responses focused on either the inner cognitive, psychological aspects of the learner and resources, characteristic of Bernstein's performance pedagogy; or on the outer, non-cognitive, sociological aspects of the learner and resources, characteristic of Bernstein's competence pedagogy.

The literature reviewed in relation to curriculum, pedagogy and Professional Dispositions offers resources to investigate and describe the nature of teachers' pedagogic discourses and the factors that shape them. Although teachers' Professional Dispositions characterised by their orientations to pedagogic practice may be essential in understanding adoption behaviours, as this paper aims to develop a conceptual framework by which teachers' tablet adoption behaviour in relation to their PD can be better understood, frameworks that deal with technology adoption relative to teachers' orientations to teaching, learning and knowledge are presented.

\section{ORIENTATION TOWARDS TABLET TECHNOLOGY}

In order to offer insights into teachers' Orientation towards Tablet Technology (OTT), various framework in which the complexity of the relationship between technology and teaching were investigated. Firstly, within the field of information technology acceptance research, the UTUAT model devised by Venkatesh, Morris, Davis, and Davis, which combines a variety of competing technology adoption models, was considered. Although this model provides a "useful tool to assess 
and manage the likelihood of success for new technology introductions and assists in understanding the driver of technology acceptance" (Venkatesh et al., 2003, p. 430), it does not provide a language by which different levels of technology adoption can be described, nor does it specifically focus on an educational context. Secondly, the Technology Pedagogical Content Knowledge (TPCK) framework, which specifically addresses the relationship between education and technology, was investigated. The TPCK, developed by Mishra and Koehler (2006), provides a framework that enables one to make sense of "complex relationships that exist when teachers attempt to apply technology to the teaching of their subject matter" [p. 1044]. However, it does not provide the language by which teachers' levels and manner of technology adoption can be described. Hooper and Rieber (1995)'s model of educational technology adoption, in which different levels and manners of technology adoption within an educational context can be identified and described, in conjunction with Bernstein (2000)'s conception of horizontal and vertical knowledge structures, is the lens through which teachers' Orientation towards Tablet Technology may be examined.

\section{LEVELS OF ADOPTION}

As discussed previously, advocates for the adoption and use of digital technology premise their claims that technology is liberating for teachers as it transforms learning and teaching within the classroom (Jaffer, 2010; Hooper \& Rieber, 1995). Fuelling these claims, proponents for the integration of educational technology contend that past educational technology reforms have resulted in technology being used simply as a support for traditional classroom activities (Cuban, 1986, 1993). Hooper and Rieber (1995) argue that educational technology should rather be a means by which to "apply ideas from various sources to create the best learning environment possible for learners" [p. 154].

To assist in further understanding the levels of technology adoption in the classroom, Hooper and Rieber (1995) developed a model by which Levels of technology Adoption (LA) could be considered. It is important at this point to note two significant core beliefs that have shaped Hooper and Rieber's views in constructing their model. Firstly, Hooper and Rieber position their model inside the dominant view, prevalent within contemporary educational technology, of pedagogic constructivism as preferable. Secondly, Hooper and Rieber's model is a stage model in which teachers need to pass from the lowest to the highest stage in a sequenced order, with the highest stage anchored by pedagogic constructivism and learner-centred views. The model is prescriptive in nature in so far as failure to follow the sequenced path would be seen, as in the past, to result in educational technology either being used incorrectly or discarded (Rieber \& Welliver, 1989). Notwithstanding these limitations, levels of educational technology adoption, as defined within Hooper and Rieber's model, provide a means by which teachers' accounts of their differing levels of technology adoption can be described.

The model is comprised of five stages defined by Hooper and Rieber as Familiarization, Utilization, Integration, Reorientation and Evolution. Familiarisation is concerned with a teacher's initial exposure to and experience with the technology. In this phase, the issues of 'how to' use the technology are addressed. The second stage, Utilization, occurs when the teacher "tries out the technology or innovation in the classroom" (Hooper \& Rieber, 1995, p. 156). While Hooper and Rieber advocate 
within this phase that teachers change their pedagogic modalities to more learner-centred and constructivist pedagogy in order to secure their effective and long term adoption, it should be clear from the preceding sections that an advocacy position for a Constructivist pedagogy as a basis for educational technology use has not been adopted in this paper.

The third stage, Integration, is where teachers consciously decide to utilize the technology and the technology is seen as indispensable to the educational process and if removed or unavailable, the teacher will be unable to proceed. Hooper and Rieber (1995) claim that this stage signals the beginning of understanding by teachers as to the value and use of technology in the classroom. Within the fourth stage, Reorientation, teachers may choose to reconceptualise and re-evaluate their pedagogic practice via examining their purpose and function in the classroom. Hooper and Rieber believe that teachers within the reorientation stage do not feel threatened about being replaced or embarrassed by the technology or the learners, but rather view technology as a tool that needs to be explored. The final stage, Evolution, provides the foundation from which teachers can examine new technologies as one of the possible resources that can enable relevant learning and teaching within a school context.

\section{MANNER OF ADOPTION}

The technological age within which we live is increasingly promoting the use of mobile technologies in all aspects of everyday life. Within an educational context, educational technology advocates assert that it is no longer sufficient to use traditional 'chalk and talk' pedagogies but rather teachers should embrace the use of technology within the classroom. Hooper and Rieber (1995) use this view as a springboard from which to describe two different types of technology use within education, Product and Idea technologies. Product technologies are usually associated with the use of traditional and contemporary audio-visual equipment, as well as print based material and computer software. Examples may include video clips, digital presentations, video and voice recordings, books, worksheets and computer-based instruction (Hooper \& Rieber, 1995). Idea technologies, on the other hand, do not have tangible forms, but are rather "represented in or through some product technology" (Hooper \& Rieber, 1995, p. 158) with the idea driving the use of a specific tool or technology. Hooper and Rieber contend that it is not the tool that determines whether the technology is a product or idea innovation but rather the teacher. The distinction between Product and Idea technologies being employed within this paper is simply as a means to identify different manners of adoption of educational technology use rather than to formulate a judgement as to nature of either as 'good or bad' (Jaffer, 2010).

\section{ADOPTION ACTIVITY}

In addition to the LA and MA, the types of activities that teachers utilize and envisage using tablet technology in the classroom, may provide a more multidimensional way through which to identify teachers' Orientation towards Tablet Technology. Many of those advocating the use of educational 
technology in the classroom have reported non-uniform adoption of technology across the teaching profession (Wang \& Reeves, 2003). Hooper and Rieber (1995) argue that the type of activity that teachers use or would like to perform with tablet technology may be closely associated with their view of the technology as either a product or an idea innovation. Drawing on Bernstein's language of description in relation to horizontal and vertical knowledge structures, we have developed additional categories in relation to Hooper and Rieber's model so as to enable the capturing of Adoption Activities.

Horizontal proficiency (AA-H) describes the teacher's ability to utilize tablet technology within their everyday lives to perform weakly classified and non-school related tasks (Bernstein, 2000); Current (AA-C) describes current activities and tasks that the teacher is using tablet technology for; and Envisaged (AA-E) describes the activities that teachers would expect to use tablet technology for in the future. Both AA-C and AA-E are dependent on teachers' horizontal proficiency or familiarisation and utilisation of the tool, as unless teachers are able to use the technology in a horizontal manner, it is unlikely that they will be able to adopt it in the classroom context (Hooper \& Rieber, 1995).

\section{CONCEPTUAL FRAMEWORK AND POSSIBLE QUESTIONS}

Frameworks facilitate the identification of items worthy of attention in the phenomenon that we are studying, the consideration of relevant issues and provide a means of classification through which insights into the nature and relationship of the objects being studied can be investigated and described (Mishra \& Koehler, 2006). The literature reviewed provides the theoretical foundation from which the conceptual framework has been constructed. This framework is intended to assist researchers interested in a more nuanced understanding of the adoption decisions made by teachers in framing questions and ensuring that there is coherence within their research studies (Green, 2014). The conceptual framework has been developed with teachers' Professional Disposition (PD) and Orientation towards Tablet Technology (OTT) as central.

The Professional Disposition (PD) of a teacher is constituted through their pedagogic discourse, which is made up of an instructional (PD-I) and regulative (PD-R) component. The instructional discourse deals with the teacher's view of their subject knowledge to be transmitted and acquired, as well as their theory of instruction, which may either be strongly or weakly classified (PD-IH or PD-IV). Sample questions for PD-I may include:

- how do you view the importance of the subject that you teach?

- does using tablet technology enhance your teaching?

- is your subject directly related to learners' everyday knowledge?

- does your subject build on previous knowledge in a systematic manner?

The regulative discourse, on the other hand, deals with the manner in which knowledge is conveyed, via different pedagogic modalities (PD-RP or PD-RC). Sample questions for PD-R may include: 


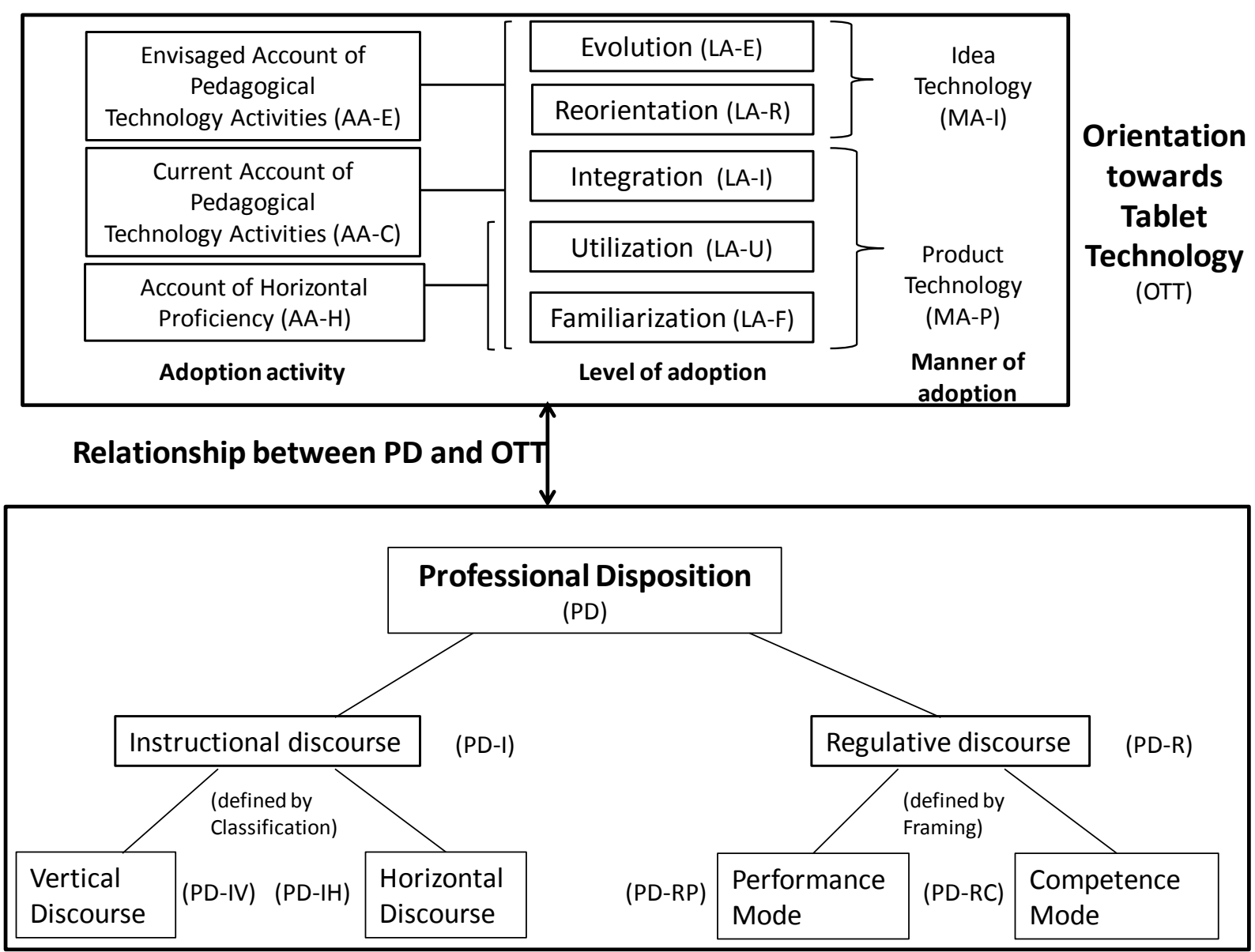

Figure 1: Conceptual framework

- your approach to teaching this subject;

- your views in relation to the teacher controlling the sequencing of lesson content;

- your views about learners controlling the pace at which they work;

- your views as to independent research or group work;

- views on learner assessment.

Orientation towards Tablet Technology (OTT), is based on Hooper and Rieber (1995)'s technological adoption model in reference to the Levels (LA-F, LA-U, LA-I, LA-R and LA-E) and Manner (MA-I or MA-P) of Adoption, as well as different adoption activities (AA-H, AA-C and AA-E) drawn from the literature reviewed. Levels of Adoption (LA) refer to the extent to which tablet technology enables 
the teacher; Manner of Adoption (MA) refers to the way in which the teacher is using the tablet technology; and Adoption Activities (AA) refers to the nature of activities that are carried out with tablet technology. Sample questions for OTT may include:

- how have you have used tablets in your personal life?

- how have you have used tablets in the classroom?

- how have you have changed your teaching due to the use of tablets? and

- whether you view the use of tablets in the classroom as a support to existing teaching practices or as a means to reorient it?

\section{APPLICATIONS OF PD AND OTT CONCEPTUAL FRAMEWORK}

This article provides a conceptual framework that can service multiple stakeholders within the educational landscape. For researchers, this framework may facilitate a more rigorous and un-biased review of teachers' technology adoption decisions in the classroom as opposed to the frequent advocacy and open-ended ethnographic studies that populate the research related to adoption of technology in the classroom. For schools, simply prescribing blanket tablet adoption policies may not be advantageous for the improvement of teaching and learning at their schools. This conceptual framework demands the acknowledgement that teachers have different Professional Dispositions and pedagogic practices and that the use of tablet technology in the classroom is not only effective and successful when teachers shift to using it as a collaborative tool. For educators, this conceptual framework provides the basis to understand their Professional Dispositions, which may provide insights into the nature and extent to which adopting tablet technology may enhance their pedagogic practices. For technologists, this conceptual framework creates the awareness that technology adoption is a human activity and teaching is not reducible to a machine, and thus when implementing technology adoption policies the human aspect needs to be carefully considered.

\section{References}

Attewell, J. (2005). From research and development to mobile learning: Tools for education and training providers and their learners. In 4th World Conference on mLearning (pp. 1-6).

Bernstein, B. (1971). On the classification and framing of educational knowledge. Knowledge and Control, 3, 245-270.

Bernstein, B. (1986). On pedagogic discourse. In I. Richardson (Ed.), Handbook of theory and research in sociology of education (pp. 205-239). Westwood: Greenwood Publishing Group.

Bernstein, B. (1996). Pedagogising knowledge: A study in recontextualisation. In Pedagogy, symbolic control and identity: Theory, research, critique. London: Taylor and Francis.

Bernstein, B. (1999). Vertical and horizontal discourse: An essay. British Journal of Sociology of Education, 20(2), 157-173. https://doi.org/10.1080/01425699995380 
Bernstein, B. (2000). Vertical and horizontal discourse: An essay. In Pedagogy, symbolic control and identity: Theory, research and critique (pp. 155-174). Rowan \& Littlefield.

Blackwell, C. (2013). Teacher practices with mobile technology: Integrating tablet computers into the early childhood classroom. Journal of Education Research, 7(4), 1-25.

Bourdieu, P. (1974). The school as a conservative force: Scholastic and cultural inequalities. Contemporary Research in the Sociology of Education, 32, 46.

Christie, P. (2008). Schools and classrooms as places of learning. In Opening the doors of learning: Changing schools in South Africa (pp. 163-208). Heinemann.

Clark, W. \& Luckin, R. (2013). What the research says: iPads in the classroom. London Knowledge Lab Report.

Clarke, B. \& Svanaes, S. (2014). An updated literature review on the use of tablets in education. Family Kids and Youth.

Clarke, B., Svanaes, S., \& Zimmermann, S. (2012). One-to-one tablets in secondary schools: An evaluation study: Stage 1: 2011-2012. Family Kids and Youth.

Cobcroft, R. S., Towers, S. J., Smith, J. E., \& Bruns, A. (2006). Mobile learning in review: Opportunities and challenges for learners, teachers, and institutions. In Proceedings Online Learning and Teaching (OLT) Conference 2006) (pp. 21-30). Brisbane: Queensland University of Technology.

Cuban, L. (1986). Teachers and machines: The classroom use of technology since 1920. Teachers College Press.

Cuban, L. (1993). Computers meet classroom: Classroom wins. Teachers College Record, 95(2), 185.

Czerniewicz, L. (2010). Educational technology-Mapping the terrain with Bernstein as cartographer. Journal of Computer Assisted Learning, 26, 523-534.

Department of Education, RSA. (2004). Notice 1869 of 2004: Draft White Paper on e-Education.

Duffy, T. M. \& Jonassen, D. H. (1992). Constructivism and the technology of instruction: A conversation. Lawrence Erlbaum Associates.

Frank, K. A., Zhao, Y., \& Borman, K. (2004). Social capital and the diffusion of innovations within organizations: The case of computer technology in schools. Sociology of Education, 77(2), 148-171. https://doi.org/10.1177/003804070407700203

Green, H. E. (2014). Use of theoretical and conceptual frameworks in qualitative research. Nurse Researcher, 21(6), 34-38. https://doi.org/10.7748/nr.21.6.34.e1252

Haßler, B., Major, L., \& Hennessy, S. (2016). Tablet use in schools: A critical review of the evidence for learning outcomes. Journal of Computer Assisted Learning, 32(2), 139-156. https://doi. org/10.1111/jcal.12123

Hoadley, U. \& Ensor, P. (2009). Teachers' social class, professional dispositions and pedagogic practice. Teaching and Teacher Education, 25(6), 876-886. https://doi.org/10.1016/j.tate.2009.01. 014

Hoadley, U. \& Muller, J. (2010). Codes, pedagogy and knowledge: Advancing Bernsteinian sociology of education. In The routledge international handbook of the sociology of education (p. 69). Routledge New York.

Hooper, S. \& Rieber, L. P. (1995). Teaching with technology. Teaching: Theory into Practice, 2013, 154-170. 
Howard, S. \& Maton, K. (2011). Theorising knowledge practices: A missing piece of the educational technology puzzle. Research in Learning Technology, 19(3), 191-206. https://doi.org/10. 3402/rlt.v19i3.17109

Jaffer, S. (2010). Educational technology pedagogy: A looseness of fit between learning theories and pedagogy. Education as Change, 14(2), 273-287. https://doi.org/10.1080/16823206. 2010.522066

Jones, C. (2010). A new generation of learners? The net generation and digital natives. Learning, Media and Technology, 35(4), 365-368. https://doi.org/10.1080/17439884.2010.531278

Kirschner, P. A., Sweller, J., \& Clark, R. E. (2006). Why minimal guidance during instruction does not work: An analysis of the failure of constructivist, discovery, problem-based, experiential, and inquiry-based teaching. Educational Psychologist, 41 (2), 75-86. https://doi.org/10.1207/ s15326985ep4102_1

Kuhn, D. (2007). Is direct instruction an answer to the right question? Educational Psychologist, 42(2), 109-113. https://doi.org/10.1080/00461520701263376

Lovászová, G., Michaličková, V., \& Cápay, M. (2015). Mobile technology in secondary education: A conceptual framework for using tablets and smartphones within the informatics curriculum. In Emerging eLearning Technologies and Applications (ICETA), 2015 13th International Conference on (pp. 1-6). IEEE. https://doi.org/10.1109/ICETA.2015.7558491

Maton, K. (2007). Knowledge-knower structures in intellectual and educational fields. In Language, knowledge and pedagogy: functional linguistic and sociological perspectives (pp. 87-108).

Mishra, P. \& Koehler, M. J. (2006). Technological pedagogical content knowledge: A framework for teacher knowledge. Teachers College Record, 108(6), 1017.

Montrieux, H., Vanderlinde, R., Schellens, T., \& De Marez, L. (2015). Teaching and learning with mobile technology: A qualitative explorative study about the introduction of tablet devices in secondary education. PloS one, 10(12), e0144008. https://doi.org/10.1371/journal.pone. 0144008

Morais, A. M. (2002). Basil Bernstein at the micro level of the classroom. British Journal of Sociology of Education, 23(4), 559-569. https://doi.org/10.1080/0142569022000038413

Motshekga, A. (2015). Second phase 'big switch on' paperless classrooms programme. Last checked: 27 Sep 2017. Retrieved from http://www.gov.za/speeches/minister-angie-motshekga2nd - phase - \%E2 \% $80 \% 98 \mathrm{big}$ - switch - on \% E2 \% $80 \% 99$ - paperless - classrooms programme-21-jul

Naidoo, D. (2011). Analysing pedagogy: Visibility and meanings. Journal of Education, (53), 37-54.

Neves, I. P. \& Morais, A. M. (2001). Knowledges and values in science syllabuses: A sociological study of educational reforms. British Journal of Sociology of Education, 22(4), 531-556.

Paczkowski, J. (2013). Apple's iTunes U hits one billion downloads. Last checked: 27 Sep 2017. Retrieved from http:/ / allthingsd.com/20130228/apples - itunes - u - hits - 1 - billion downloads/

PDST: Technology in Education. (2017). Tablets for learning. Last checked: 02 Oct 2017. Retrieved from https://goo.gl/QzHLAq 
Perkins, D. N. (1992). Technology meets constructivism: Do they make a marriage. In Constructivism and the technology of instruction: a conversation (pp. 45-55).

Polit, D. F. \& Beck, C. T. (2010). Essentials of nursing research: Appraising evidence for nursing practice. Lippincott Williams \& Wilkins.

Prensky, M. (2001). Digital natives, digital immigrants part 1. On the Horizon, 9(5), 1-6. https: //doi.org/10.1108/10748120110424816

Ravenscroft, A. (2001). Designing e-learning interactions in the 21st century: Revisiting and rethinking the role of theory. European Journal of Education, 36(2), 133-156.

Reiser, R. A. (2001). A history of instructional design and technology: Part I: A history of instructional media. Educational Technology Research and Development, 49(1), 53-64. https://doi.org/10. 1007/BF02504506

Rieber, L. \& Welliver, P. W. (1989). Infusing educational technology into mainstream educational computing. International Journal of Instructional Media, 16(1), 21-32.

Roschelle, J. M., Pea, R. D., Hoadley, C. M., Gordin, D. N., \& Means, B. M. (2000). Changing how and what children learn in school with computer-based technologies. The Future of Children, 76-101. https://doi.org/10.2307/1602690

Scott, D. (2007). Critical essays on major curriculum theorists. Routledge.

Singh, P. (2002). Pedagogising knowledge: Bernstein's theory of the pedagogic device. British Journal of Sociology of Education, 23(4), 571-582. https://doi.org/10.1080/0142569022000038422

Swan, K. (2005). A constructivist model for thinking about learning online. Elements of Quality Online Education: Engaging Communities, 6, 13-31.

Venkatesh, V., Morris, M. G., Davis, G. B., \& Davis, F. D. (2003). User acceptance of information technology: Toward a unified view. MIS Quarterly, 425-478.

Von Glasersfeld, E. (1998). Cognition, construction of knowledge, and teaching. In Constructivism in science education (pp. 11-30). Springer. https://doi.org/10.1007/978-94-011-5032-3_2

Wang, F. \& Reeves, T. C. (2003). Why do teachers need to use technology in their classrooms? Issues, problems, and solutions. Computers in the Schools, 20(4), 49-65. https://doi.org/10.1300/ J025v20n04_05

Whitefield, T. (2012). Pedagogy in the evolving tech environment-What has changed? In Proceedings of International Conference on Information Communication Technologies in Education (ICICTE) (p. 283). 